\title{
SAGRADO E AS DROGAS PSICOATIVAS SOB A OTICA DAS RELIGIÕES DE MATRIZ AFRICANA
}

\author{
The sacred and psychoactive drugs from tge perspective of african religions
}

\author{
Diogo Jacintho Barbosa ${ }^{1}$ \\ Antonio Marcos Tosoli Gomes ${ }^{2}$ \\ Marcia Pereira Gomes ${ }^{3}$ \\ Juliana de Lima Brandão ${ }^{4}$
}

\begin{abstract}
RESUMO
Introdução: O conceito de saúde utilizado atualmente versa sobre o cuidado integral, que visa não somente alcançar o ser humano no que tange às suas doenças, como ainda seu social e seu mental, definindo-se assim o ser humano como biopsicossocial espiritual. Objetivos: identificar o conhecimento dos fiéis sobre as religiões de matriz africana a respeito das drogas psicoativas e de seus usuários e analisar as implicações desse conhecimento no cuidado em saúde e enfermagem. Métodos: Este trata-se de um estudo misto exploratório sequencial. Resultados: A partir da coleta de dados foi possível identificar que para as religiões de matriz africana o uso de drogas psicoativas de maneira abusiva é considerado como fator limitador da conexão com o divido, devendo o "fiel" procurar ajuda física e espiritual para se ver livre desta utilização .Conclusões: A profissão de Enfermagem é definida por muitos como a ciência do cuidado e do cuidar que além do cuidado com o corpo, também deve privilegiar as diversas áreas da vida humana, incluindo-se a dimensão religiosa/espiritual.
\end{abstract}

Palavras-chave: religiosidade, espiritualidade, drogas psicoativas, enfermagem.

\begin{abstract}
Introduction: The concept of health currently used is about comprehensive care, which aims not only to reach the human being with regard to their diseases, but also their social and mental, thus defining the human being as a spiritual biopsychosocial. Objectives: to identify the knowledge of the faithful of African religions regarding psychoactive drugs and their users and to analyze the implications of this knowledge in health and nursing care. Methods: This is a mixed sequential exploratory study. Results: From the data collection it was possible to identify that for African religions the use of psychoactive drugs in an abusive way is considered as a limiting factor of the connection with the debt, and the "faithful" should seek physical and spiritual help to see free from this use. Conclusions: The nursing profession is defined by many as the science of care and care, which in addition to caring for the body,

\footnotetext{
${ }^{1}$ Enfermeiro, Doutor em Enfermagem pelo Programa de Pós-Graduação em Enfermagem da Universidade do Estado do Rio de Janeiro-UERJ. Mestre em Telessaúde. Professor assistente do Centro Universitário Gama e Souza

2 Professor do Departamento de Enfermagem Médico-Cirúrgica e do Programa de Pós-Graduação em Enfermagem, Faculdade de Enfermagem, Universidade do Estado do Rio de Janeiro-UERJ, Brasil.

${ }^{3}$ Enfermeira. Mestre em Enfermagem pelo Programa de Pós-Graduação em Enfermagem da Universidade Federal do Estado do Rio de Janeiro (UNIRIO)

${ }^{4}$ Enfermeira. Mestre em Enfermagem pelo Programa de Pós-graduação em Enfermagem da Universidade do Estado do Rio de Janeiro - UERJ, Brasil. Especialista em Enfermagem do Trabalho pela Escola de Enfermagem Aurora de Afonso Costa da Universidade Federal Fluminense - EEAAC/UFF
} 
should also privilege the different areas of human life, including the religious / spiritual dimension.

Keywords: religiosity, spirituality, psychoactive drugs, nursing.

\section{Introdução}

O uso de drogas psicoativas existe desde o princípio da história do homem e diversos fatores estão atrelados ao início, à manutenção e à continuação da sua utilização, dentre os quais se destacam: curiosidade, desejo de transcendência e as buscas pela imortalidade, pelo prazer e pela sabedoria (GOMES-MEDEIROS, 2019). Podemos definir drogas psicoativas de maneira geral como qualquer substância que ao penetrar no corpo é capaz de alterar o comportamento, humor e a cognição, mudando assim o modo em que usuário se percebe e vislumbra o mundo durante o tempo de ação destas substâncias, que por consequência são capazes de gerar vício (BARBOSA, 2021). Estima-se que um total de 246 milhões de pessoas - um pouco mais que 5\% da população mundial com idade entre 15 e 64 anos - tenham feito uso de drogas ilícitas em 2013 (SILVA, 2012). Ainda pode-se destacar que a utilização de drogas psicoativas tem sido um fator colaborador para o aumento da taxa de mortalidade geral, uma vez que os números estimavam um total de 187.100 mortes de 2013 até 2015 relacionadas ao consumo abusivo de drogas psicoativas (SILVA, 2012; SEPREDEQ, 2014). Esses fatos colaboraram para que o uso de drogas psicoativas de maneira abusiva fosse encarado como um problema de saúde pública.

O reconhecimento da utilização das drogas psicoativas como um problema de saúde pública levou a uma reformulação no modelo de tratamento empregado pelas unidades de saúde, denominada Reforma Psiquiátrica. No Brasil, essa reforma atrelou o tratamento dos usuários de drogas psicoativas às unidades básicas de saúde, como também aos hospitais gerais além disso, classificou a utilização de drogas psicoativas de maneira abusiva como doença, tendo em vista os diversos transtornos mentais que surgem em decorrência destas.

O conceito de saúde utilizado atualmente versa sobre o cuidado integral, que visa não somente alcançar o ser humano no que tange às suas doenças, como ainda seu social. seu mental e o seu espiritual, definindo-se assim o ser humano como biopsicossocial espiritual (VIEIRA, 2017).

No tocante à enfermagem, as questões referentes à religiosidade e espiritualidade no cuidar surgiram pelos esforços da enfermeira Wanda Aguiar Horta, que se espelhou em Maslow para a criação da Teoria das Necessidades Humanas Básicas, colocando a 
espiritualidade e a religiosidade como necessidades básicas do ser humano (PETERSEN, 2019; OLIVEIRA, 2011).

Assim, entendendo que o ser humano é um ser biopsicossocial-espiritual, bem como também a religiosidade e espiritualidade se configurando como uma necessidade básica e ainda a definição de saúde para além do físico e ausência de doenças é necessário que os profissionais de saúde apresentem artifícios que os favoreçam a prestar um cuidado que englobe as dimensões espirituais e religiosas.

Entretanto, a inserção da religiosidade e da espiritualidade no contexto do cuidado do usuário de drogas psicoativas nem sempre é algo fácil, tendo em vista que, em sua maioria, os profissionais de enfermagem não foram treinados para tal (MODELL, 2020; GUILHERME, 2016).

As religiões de matriz africana escolhidas para este estudo são a umbanda e o candomblé. De modo geral podemos dizer que tanto a umbanda quanto o candomblé não são as únicas religiões africanas no Brasil, porém de acordo com o Censo realizado pelo IBGE em 2010 (último censo demográfico brasileiro), estas são as religiões com maior número de fiéis (IBGE, 2010).

A Umbanda é conhecida como religião tipicamente brasileira, tendo em vista que está foi criada no Brasil a partir de um racha na religião candomblé que foi trazida pelos escravos durante o período de colonização no Brasil. Estas religiões apresentam semelhanças e disparidades, porém bebem da mesma fonte e são consideradas religiões populares e que circulam entre a cultura brasileira (MORAES, 2017), justificando assim a escolha destas religiões para realização deste estudo.

Essas religiões, apesar de utilizarem o álcool (uma substância psicoativa) e o cigarro como elementos que compõem o sagrado, é sabido pelos fiéis da religião que estes são utilizados apenas como elemento para obter força e energia para aplicá-los nas conduções de seus trabalhos religiosos, no bem e na caridade (ROCHA, 2019). Assim, tanto na umbanda quanto no candomblé existem tratamentos espirituais para auxiliar seus fiéis a se afastarem do consumo de drogas psicoativas (BARBOSA, 2021).

A partir dessas premissas, o presente estudo buscou entender a relação das drogas psicoativas com as religiões de matriz africana no Brasil, uma vez que estas vêm crescendo exponencialmente em número de fiéis, sobretudo nos grandes centros urbanos, de modo que possa se propor um cuidado em saúde que seja capaz de abranger o ser humano como um todo, reforçando a definição deste como ser biopsicossocial-espiritual (MARQUES, 2003). 
Assim, a utilização de ferramentas religiosas no cuidar em saúde, ao mesmo tempo que se insere no espiritual, apresenta também aspectos sociais.

Para tanto, foram elencados os seguintes objetivos: identificar o conhecimento dos fiéis das religiões de matriz africana a respeito das drogas psicoativas e de seus usuários e analisar as implicações desse conhecimento no cuidado em saúde e enfermagem.

\section{Material e métodos}

Este trata-se de um estudo misto do tipo exploratório sequencial. Os estudos mistos podem ser entendidos como uma modalidade de estudos, onde se empregam ferramentas quantitativas e qualitativas de modo que essas se complementam e facilitam a análise da totalidade dos dados (SANTOS, 2017).

Para a realização deste estudo, adotou-se como instrumento de coleta de dados a entrevista semiestruturada. Foram entrevistados 5 sujeitos de grupos religiosos de matriz africana (umbanda e candomblé), o que possibilitou a análise do corpus e, posteriormente, a criação de categorias a fim de facilitar o entendimento da representação social para cada grupo religioso pertencente ao estudo. Aqui serão descritos apenas os resultados que dizem respeito aos sujeitos de matriz africana. Como critério de inclusão, adotou-se: indivíduos com idade igual ou superior a 18 anos, com pertença de, no mínimo, seis meses ao grupo religioso e que desejassem participar de forma voluntária deste estudo. Para eles, foi oferecido o Termo de Consentimento Livre e Esclarecido (TCLE) para preenchimento. Os participantes são identificados por número pela ordem que foi realizada a entrevista.

Este artigo trata-se de um recorte da tese de doutorado dos autores do estudo apresentada como requisito básico para a obtenção do título de Doutor de um Programa de Pós-Graduação em Enfermagem de uma Universidade Estadual do Rio de Janeiro (Brasil).

O estudo foi aprovado pelo Comitê de ética em pesquisa sob o parecer no 3.121 .454 e CAAE 06246419.7.1001.8144.

\section{Discussão e Resultados}

As religiões de matriz africana aqui abordadas são representadas pela umbanda e pelo candomblé. Participaram desta etapa do estudo quatro sujeitos, dois fiéis da Umbanda e dois fiéis do Candomblé, todos do sexo feminino, com idade entre 20 e 35 anos e com tempo de pertença média à religião de três anos. 
A análise da entrevista semiestruturada, para os umbandistas, deixa claro que, nada é falado diretamente a respeito do consumo de drogas e do álcool, nem a respeito de que maneira seus usuários devem ser tratados dentro dos preceitos religiosos. Esse fato pode ser observado na fala do participante,

"na minha religião não é falado nada diretamente sobre o uso de drogas. Penso que é porque todos são livres para fazer o que pretendem fazer, independente do que os outros achem. (****id_9 *sex_2 *religião_5).

Os participantes descrevem que essa religião não condena o uso social, apenas o consumo definido como prejudicial, e ainda definem o consumo prejudicial como consumo excessivo, conforme pode-se observar na fala de outro participante,

Oficialmente, minha religião não condena o uso destas substâncias, apenas diz que devemos evitar o consumo prejudicial. Quando digo consumo prejudicial, quero dizer aquele em excesso, pois tudo que passa da medida certa é prejudicial (****id_10 *sex_2 *religião_5).

"na minha religião não é falado nada diretamente sobre o uso de drogas. Penso que é porque todos são livres para fazer o que pretendem fazer, independente do que os outros achem”. (****id_9*sex_2 *religião_5).

A fala dos participantes acima corrobora com a noção de livre arbítrio apontada por Diebe (2019) e presente também nos grupos religiosos de matriz africana, candomblé, umbanda e suas ramificações, assim para a fé de matriz africana e suas ramificações, Deus deu ao homem o livre-arbítrio para que ele pudesse ter consciência de seus atos, de seus pensamentos e as consequências disso. Então, o destino nada mais é do que fruto desse livrearbítrio. [...] o caminho é livre, mas depende de nosso esforço (DIEBE, 2019)

Nossos atos e as consequências deles são fruto do livre-arbítrio, como também a preferência pela utilização ou não das drogas. O homem tem plena liberdade de escolha sobre suas decisões, como afirmam os participantes:

“cada um usa a droga como quiser e quando quiser. É claro que é algo ruim, mas a pessoa que sabe da sua vida” (****id_9*sex_2 *religião_5). 
“que temos nosso livre arbítrio, podemos escolher usar ou não. Deus não se mete nisso" (****id_11*sex_2 *religião_5).

Desse modo, percebemos que diversos fatores podem estimular o indivíduo ao uso dessas substâncias, porém a escolha final vem dele mesmo, com base no livre-arbítrio, conforme acreditam os fiéis dessa doutrina participante deste estudo. Para indivíduos que já se utilizaram dessas substâncias e estão em recuperação, a crença nos orixás é apontada como fator de fortalecimento para passar pelo momento da abstinência com sucesso, como pode-se observar na fala abaixo:

"há os orixás. Meus orixás me dão muita força, sabe, para suportar qualquer coisa sem precisar (me) recorrer às drogas” (****id_9*sex_2 *religião_5).

Diferentemente do encontrado nas outras religiões como o catolicismo e o protestantismo, nesse grupo religioso foi possível observar, na fala das fiéis, a utilização do álcool em rituais religiosos, porém essa não é feita por eles, e sim pelas entidades no momento de "transe e/ou incorporação", como destacado na fala do participante, a seguir:

ah tem entidades que bebem e fumam no momento da gira, mas faz parte da cultura daquela entidade, não é a pessoa que está bebendo nem fumando. Isso acontece muito no meu barracão, ou melhor, no barracão de toda comunidade de Umbanda. Faz parte da essência daquele santo (****id_9 *sex_2 *religião_5).

Há estudos que evidenciam que a utilização das drogas, no momento da gira (um tipo de ritual de umbanda para realização de trabalhos espirituais por meio de médiuns que incorporam entidades), pelos orixás, não está pautada na droga, na substância, e, sim, na manipulação dos elementos vegetais que estão presentes na preparação dessas substâncias, de modo a extrair a energia deles para fazer a ligação entre a entidade e o espírito consulente (DA SILVA, 2017).

Tal qual aconteceu na umbanda, no candomblé, os sujeitos afirmam não conhecer questões especificas, em sua religião, a respeito das drogas ou da utilização do álcool. Porém, quando o assunto é mencionado no âmbito do centro religioso, geralmente está relacionado à obsessão. 
De fato, igualmente ao acontecido na umbanda, o consumo de álcool e de drogas lícitas e ilícitas não é proibido, condenando-se apenas os excessos, como podemos observar abaixo:

"infelizmente o que geralmente ouvimos é uma associação do alcoolismo com problemas espirituais, como as questões de obsessão” (*****id_14 *sex_2 *religião_6).

"candomblé nos ensina que tudo que é feito em excesso adoece o corpo, enfraquece, trazendo diversos transtornos” $(* * * * *$ id_3 3 sex_2 *religião_6).

Para os candomblecistas, os excessos na utilização do álcool e das drogas são capazes de levar o indivíduo à dependência, ao vício, e esta, segundo os fiéis, é prejudicial às saúdes física e espiritual. Para esse grupo religioso, a dependência ainda se pauta na falsa ideia de plenitude ligada às drogas (BARBOSA, 2021), da mesma forma que é observado na fala de outro participante,

a dependência está relacionada ao enfraquecimento da mente. A pessoa perdida, necessitando um novo rumo, com diversos problemas, e o que a torna dependente é que ela acredita que nada mais do que aquele vai trazer a sensação de estar completo. Por isso é tão difícil o tratamento, é tão difícil utilizar o lado religioso. É uma luta constante para trazer a pessoa para esta realidade, de que ela pode confiar nela mesmo. (*****id_3 *sex_2 *religião_6).

Quando comparado aos umbandistas, os candomblecistas descreveram a relação entre os orixás, a substância e a pessoa que consome, como pode ser notado nas falas abaixo:

creio que Olórùn, também chamado Deus, e os Orixás não classificam de forma negativa estas pessoas. Acho que estas grandiosas Forças têm a missão de proteção, de cuidado, de auxílio e não de castigo, como alguns religiosos insistem em dizer. Ninguém é castigado com vícios pelo Orixá ou por Deus. Estamos em evolução, onde diversas situações ocorrem para vermos se somos capazes de superá-las. Algumas pessoas não conseguem superar situações para ter a evolução e então necessitam de ajuda. (**** *id_14 *sex_2 *religião_6).

os Ewó, também chamados de tabus ou proibições ou dogmas, são uma forma de trazerem uma regra para aquele que faz parte de nossa religião. Somos orientados sobre estes Ewó através das lendas dos Orixás, das lendas de Ifá, e em diversas passagens encontramos orientações sobre o vício, a 
dependência e a importância de controlarmos estas questões para que não tenhamos uma vida ruim $\left(* * * * * i d \_3 *\right.$ sex_2 *religião_6).

A relação descrita entre o fiel, o ser transcendente e a substância reflete uma situação de amizade entre o orixá e o fiel, de modo a fortalecê-lo para resistir às tentações relacionadas às drogas. Essa relação, no candomblé, intensifica-se a partir da iniciação, que é definida como um recurso terapêutico, cujo objetivo é possibilitar ao indivíduo artifícios para lidar com questões do seu cotidiano (MARQUES, 2018).

Tanto a umbanda quanto o candomblé incentivam o indivíduo a buscar ajuda espiritual e médica, fazendo um intercâmbio entre as dimensões transcendental e institucional, nota-se isso nas falas,

apesar de utilizarmos bebidas como elementos sagrados, não concordamos com os vícios, com o uso excessivo de bebidas que podem trazer problemas familiares, afetar a questão de concentração e dedicação (*****id_3 *sex_2 *religião_6).

consideramos que as pessoas dependentes necessitam dentro da religião de ajuda espiritual, ajuda emocional e acompanhamento médico (*****id_14 *sex_2 *religião_6).

Tal qual observado na fala do participante id_3, o álcool é utilizado nos ritos religiosos do candomblé, sendo considerado elemento sagrado, porém, igualmente na umbanda, ele não é utilizado como forma recreativa e, sim, para fazer a conexão do orixá com o consulente.

Apesar da umbanda e do candomblé tratarem-se de religiões de matriz africana distintas, foi possível observar algumas diferenças no que tange principalmente o tratamento para atualização abusiva de drogas psicoativas, uma vez que para os candomblecistas esta utilização é vista diretamente como doença, sendo necessário recorrer a ajuda médica; por outro lado, para os umbandistas ficou evidente a necessidade de cura religiosa e espiritual para tal consumo abusivo.

\section{Conclusão}

As religiões de matriz africana fazem parte da cultura e história do povo brasileiro, e os fiéis a essa religião estão presentes em todas as classes sociais, assim os ensinamentos e práticas dessa religião influenciam diretamente na vida dos indivíduos em diversas questões, como a saúde, destacada aqui neste estudo. 
Destaca-se que esses grupos religiosos repudiam o consumo abusivo de drogas psicoativas, entretanto ficou evidente que sua religião apresenta artifícios capazes de auxiliar os indivíduos a lidar com os motivos que o levaram ao consumo de drogas psicoativas, em consonância com diversos estudos que enfocam a religiosidade e a espiritualidade como fator de proteção para o consumo de droga psicoativas.

A enfermagem é uma profissão ligada diretamente ao cuidar, e as características do seu trabalho favorecem um maior tempo de interação com o paciente, criando-se várias oportunidades para que se possa entender como a religiosidade e espiritualidade influenciam na vida de cada um, de modo a utilizar-se de ferramentas espirituais no cuidar para fortalecer não só o cliente, como também o profissional. A profissão de enfermagem é definida por muitos como a ciência do cuidado e do cuidar que além do cuidado com o corpo, também deve privilegiar as diversas áreas da vida humana, incluindo-se a dimensão religiosa/espiritual.

Em relação às práticas de saúde, fica evidente a existência de diversos fatores capazes de interferir no binômio saúde e doença, dentre os quais podemos elencar: fatores sociais, psicológicos e espirituais. Assim, os profissionais de saúde devem desenvolver artifícios capazes de contemplar as diversas áreas da vida dos indivíduos. Dessa forma, as questões religiosas e espirituais também devem ser empregadas como ferramenta de suporte ao cuidado.

Portanto, para que isso ocorra, julga-se necessária a inserção dessas ferramentas na formação dos profissionais de saúde, sobretudo os profissionais de enfermagem, que por características da profissão, permanecem um maior tempo ao lado do paciente.

Além da inserção destas ferramentas nas práticas de cuidar, percebemos também que julga-se necessária a criação de políticas públicas de saúde que privilegiem as diversas áreas do cuidar com foco na integralidade, enfocando assim esferas que vão para além do binômio saúde e doença.

\section{REFERÊNCIAS}

BARBOSA, Diogo Jacintho et al. Onde as religiões se encontram: um estudo de representações sociais das drogas psicoativas e suas implicações para no cuidado em enfermagem. Research, Society and Development, v. 10, n. 1, p. e17310110982, 2021.

DA SILVA, Renan Antônio. Preciso de Ti: A relevância da religião no combate (reabilitação) às drogas. Protestantismo em Revista, v. 43, n. 01, p. 184, 2017. 
DIEBE, Edsel Pamplona. O livre-arbítrio na ética de Abelardo. Trans/Form/Ação, v. 42, n. spe, p. 231-248, 2019.

GOMES-MEDEIROS, Débora, FARIA, Pedro Henrique de, CAMPOS, Gastão Wagner de Sousa, et al. Política de drogas e Saúde Coletiva: diálogos necessários. Cadernos de Saúde Pública, vol. 35, n. 7, 2019.

GUILHERME, Lucas Tetzalff de Gerone. A religiosidade/espiritualidade na prática do cuidado entre profissionais da saúde. Interações, v. 11, n. 20, p. 129, 2016.

IBGE - Instituto Brasileiro de Geografia e Estatística, 2010. Pesquisa Nacional por Amostra de Domicílios - 2010. Rio de Janeiro: IBGE.

MARQUES, L. A saúde e o bem-estar espiritual em adultos porto-alegrenses. Psicologia: Ciência e Profissão, v. 23, n. 2, p. 56-65, 2003.

MARQUES, Lucas. Fazendo orixás: sobre o modo de existência das coisas no candomblé. Religião \& Sociedade, vol. 38, n. 2, p. 221-243, 2018.

MODELL, Stephen M.; KARDIA, Sharon L. R. Religion as a Health Promoter During the 2019/2020 COVID Outbreak: View from Detroit. Journal of Religion and Health, vol. 59, n. 5, p. 2243-2255, 2020.

MORAIS, M.; JAYME, J. Povos e comunidades tradicionais de matriz africana: uma análise sobre o processo de construção de uma categoria discursiva. Civitas - Revista de Ciências Sociais, v. 17, n. 2, p. 268, 2017.

OLIVEIRA, Barbara Campos de; GARANHANI, Mara Lúcia; GARANHANI, Márcia Regina. Cuidador de pessoa com acidente vascular encefálico: necessidades, sentimentos e orientações recebidas. Acta Paulista de Enfermagem, vol. 24, n. 1, p. 43-49, 2011.

PETERSEN, Cristina Buischi, LIMA, Regina Aparecida Garcia; BOEMER, Magali Roseira, et al. Necessidades de saúde e o cuidado de enfermagem. Revista Brasileira de Enfermagem, vol. 69, n. 6, p. 1236-1239, 2016.

ROCHA, Matheus Barbosa da; SEVERO, Ana Kalliny De Sousa; FÉLIX-SILVA, Antônio Vladimir. Nos batuques dos quintais: as compreensões dos povos de Umbanda sobre saúde, adoecimento e cuidado. Physis: Revista de Saúde Coletiva, vol. 29, n. 3, 2019.

SANTOS, José Luís Guedes dos, et al. Integração Entre Dados Quantitativos e Qualitativos em uma Pesquisa de Métodos Mistos. Texto \& Contexto - Enfermagem, vol. 26, n. 3, 2017. Secretaria de Estado de prevenção à Dependência Química (Sepredeq), S. d. (26 de junho, 2014). Governo do Estado do Rio de Janeiro.

SILVA, Caroline Cordeiro Viana E. Relatório Mundial sobre drogas, 2012. Conjuntura Global, vol. 1, n. 1, 2012.

VIEIRA, Fernanda De Sousa, MINELLI, Massimiliano, CORRADI-WEBSTER, Clarissa Mendonça. Consumo de drogas por pessoas com diagnósticos psiquiátricos: percursos 
possíveis em uma rede de atenção psicossocial. Physis: Revista de Saúde Coletiva, vol. 27, n. 4, p. 1243-1263, 2017. 